\title{
Homocysteine affects cardiomyocyte viability: concentration-dependent effects on reversible flip-flop, apoptosis and necrosis
}

\author{
Jessica A. Sipkens · Paul A. J. Krijnen · Christof Meischl • Saskia A. G. M. Cillessen • \\ Yvo M. Smulders · Desirée E. C. Smith · Cindy P. E. Giroth - Marieke D. Spreeuwenberg • \\ René J. P. Musters · Alice Muller · Cornelis Jakobs · Dirk Roos · Coen D. A. Stehouwer · \\ Jan A. Rauwerda $\cdot$ Victor W. M. van Hinsbergh $\cdot$ Hans W. M. Niessen
}

Published online: 18 April 2007

(C) Springer Science+Business Media, LLC 2007

\begin{abstract}
Background Hyperhomocysteinaemia (HHC) is thought to be a risk factor for cardiovascular disease including heart failure. While numerous studies have analyzed the role of homocysteine (Hcy) in the vasculature, only a few studies investigated the role of Hcy in the heart. Therefore we have analyzed the effects of Hcy on isolated cardiomyocytes. Methods H9c2 cells (rat cardiomyoblast cells) and adult rat cardiomyocytes were incubated with Hcy and were analyzed for cell viability. Furthermore, we determined the effects of Hcy on intracellular mediators related to cell viability in cardiomyocytes, namely NOX2, reactive oxygen species (ROS), mitochondrial membrane potential $\left(\Delta \Psi_{\mathrm{m}}\right)$ and ATP concentrations.
\end{abstract}

J. A. Sipkens ( $₫)$ · P. A. J. Krijnen · C. Meischl ·

S. A. G. M. Cillessen - C. P. E. Giroth •

H. W. M. Niessen

Department of Pathology, VU University Medical Centre,

Room 0E46, De Boelelaan 1117, Amsterdam 1081 HV,

The Netherlands

e-mail: j.sipkens@vumc.nl

\section{Y. M. Smulders}

Internal Medicine, VU University Medical Centre,

Amsterdam, The Netherlands

D. E. C. Smith · C. Jakobs

Clinical Chemistry, VU University Medical Centre,

Amsterdam, The Netherlands

M. D. Spreeuwenberg

Epidemiology and Biostatistics, VU University Medical Centre,

Amsterdam, The Netherlands

R. J. P. Musters · A. Muller · V. W. M. van Hinsbergh Department of Physiology, VU University Medical Centre, Amsterdam, The Netherlands
Results We found that incubation of $\mathrm{H} 9 \mathrm{c} 2$ cells with $0.1 \mathrm{mM}$ D,L-Hcy ( $=60 \mu \mathrm{M} \mathrm{L}-\mathrm{Hcy})$ resulted in an increase of $\Delta \Psi_{\mathrm{m}}$ as well as ATP concentrations. $1.1 \mathrm{mM}$ D,L-Hcy $(=460 \mu \mathrm{M}$ L-Hcy $)$ induced reversible flip-flop of the plasma membrane phospholipids, but not apoptosis. Incubation with $2.73 \mathrm{mM}$ D,L-Hcy (= $1.18 \mathrm{mM} \mathrm{L}-\mathrm{Hcy})$ induced apoptosis and necrosis. This loss of cell viability was accompanied by a thread-to-grain transition of the mitochondrial reticulum, ATP depletion and nuclear NOX2 expression coinciding with ROS production as evident from the presence of nitrotyrosin residues. Notably, only at this concentration we found a significant increase in S-adenosylhomocysteine which is considered the primary culprit in HHC.

\section{D. A. Stehouwer}

Department of Internal Medicine, Academic Hospital

Maastricht, Maastricht, The Netherlands

J. A. Rauwerda

Department of Vascular Surgery, VU University Medical Centre,

Amsterdam, The Netherlands

H. W. M. Niessen

Department of Cardiac Surgery, VU University Medical Centre, Amsterdam, The Netherlands

J. A. Sipkens · P. A. J. Krijnen - C. Meischl ·

Y. M. Smulders · R. J. P. Musters · A. Muller .

C. Jakobs - J. A. Rauwerda - V. W. M. van Hinsbergh .

H. W. M. Niessen

ICaR-VU, Institute of Cardiovascular Research,

VU University Medical Centre, Amsterdam, The Netherlands

D. Roos

Sanquin Research at CLB and Landsteiner Laboratory,

Academic Medical Centre, University of Amsterdam,

Amsterdam, The Netherlands 
Conclusion We found concentration-dependent effects of Hcy in cardiomyocytes, varying from induction of reversible flip-flop of the plasma membrane phospholipids, to apoptosis and necrosis.

Keywords Hyperhomocysteinaemia - Cardiomyocytes . Heart failure · Oxidant stress · Apoptosis

\section{Introduction}

Hyperhomocysteinaemia (HHC) reflects an impairment of the methionine-homocysteine metabolism. Normally homocysteine (Hcy) is converted to cysteine via transsulfuration or to methionine by addition of a methyl group donated by folate [1]. However, when these pathways are deranged because of genetic mutations of enzymes involved or relative deficiencies of folate, vitamin B6 or vitamin B12, the serum concentration of Hcy increases [2, 3].

In 1969 Mc Cully et al. reported elevated concentrations of Hcy in young patients with severe cardiovascular disease [4]. They hypothesized the existence of a pathogenic link between HHC and atherogenesis. Since then other studies have also suggested that HHC is an independent risk factor for cardiovascular complications [5-8]. It is now assumed that even mild HHC constitutes an independent risk factor for cardiovascular disease [9] with equal predictive strength as hypercholesterolemia and smoking [10]. Whether Hcy itself or a Hcy-related substance such as S-adenosyl-homocysteine ( $\mathrm{SAH}$ ) is the culprit, and what the exact pathogenic mechanism of the cardiovascular complications induced by HHC could be, remains to be elucidated. In addition, large-scale intervention trails using high-dose-B-vitamins to reduce plasma Hcy levels in cardiovascular patients have as yet not shown an overall clinical benefit [11-13]. This raises further questions about the mechanisms underlying the association between HHC and cardiovascular disease, and about the possible adverse effects of high-dose-B-vitamins as a means of reducing Hcy levels [14].

Studies on the effects of Hcy on the vascular wall, especially on endothelial and smooth muscle cells, indicate that increased Hcy leads to cellular stress and also to cell damage [15-17]. Hcy primes human neutrophils for an increased production of reactive oxygen species (ROS) and induces ROS production in endothelial cells $[15,18]$. ROS production has also been found in the vascular wall of coronary arteries during HHC [19] and a role of NADPH oxidases in this process has been suggested.

From the Framingham Heart Study it is known that increased plasma homocysteine concentrations, next to their effect on the vasculature, also form an independent risk factor for the development of heart failure [20]. Several other studies have also shown a link between HHC and heart failure [21, 22]. However, so far no studies have addressed possible effects of Hcy on cardiomyocytes. Therefore, we performed the present study to analyze the effects of Hcy on isolated cardiomyocytes.

\section{Materials and methods}

\section{Cell cultures}

Rat cardiomyoblasts (H9c2 (2-1) cells; ATCC, Manassas, VA, USA) were cultured in Dulbecco's Modified Eagles Medium (DMEM; BioWhittaker, Verviers, Belgium) supplemented with $10 \%$ heat-inactivated fetal calf serum (FCS; BioWhittaker), 2 mM L-glutamine (GIBCO, Paisley, UK), $100 \mathrm{IU} / \mathrm{ml}$ penicillin (Yamanouchi Europe BV, Leiderdorp, Netherlands) and $100 \mu \mathrm{g} / \mathrm{ml}$ streptomycin (Radiopharma-Fisiopharma, Palomonte, Italy), and grown at $37^{\circ} \mathrm{C}$ in a humidified $5 \% \mathrm{CO}_{2} / 95 \%$ air atmosphere. Experiments were performed with cells grown to a confluency of 60-80\%. Adult rat cardiomyocytes were isolated as described before [23].

\section{Antibodies and chemicals}

Monoclonal Antibody 48 against NOX2 IgG 1 (dilution 1:28) was obtained from Sanquin Research at CLB, Amsterdam, The Netherlands [24]. Cy3-labeled goat-antirabbit-Ig (1:75) (Alexa Fluor; Leiden, Netherlands) was used as a secondary antibody. Polyclonal $\alpha$-Nitrotyrosine IgG (1:50) (Molecular Probes Inc, Eugene, OR, USA) was used as an antibody to measure nitrotyrosin residues which is an indicator for ROS production. In this case, Cy5-labeled goat-anti-rabbit-Ig (1:50) (Jackson Immuno Research, West Grove, PA, USA) was used as a secondary antibody. Isotype controls and PBS were used to determine aspecific binding. Monoclonal antibody 1501R against pan-actin (1:6000; Chemicon International, Inc, Temecula, CA, USA) was used as a loading control for the western blot analysis.

Cells were incubated with several concentrations (0.1 mM-2.7 mM) of D,L-homocysteine (Hcy) (Sigma, St. Louis, MO, USA) in growth medium for $24 \mathrm{~h}$ at $37^{\circ} \mathrm{C}$ in a humidified $5 \% \mathrm{CO}_{2} / 95 \%$ air atmosphere.

Measuring Hcy concentration in growth medium

The H9c2 cells were incubated with different concentrations of D,L-Hcy. Several studies have suggested that only the $\mathrm{L}$ form is bioactive $[25,26]$. Next to D,L-Hcy concentration we therefore also measured the L-form. D,L-Hcy was measured by HPLC using fluorescence detection [27]. 
Intra- and interassay coefficients of variation (CVs; std dev/average $* 100 \%$ ) were 1.8 and $3.5 \%$, respectively. L-Hcy was measured by the Abbott IMx fluorescence polarization immunoassay (IMx; Abbott Laboratories, Abbott Park, IL, USA). Intra- and interassay CVs were less than 2 and 4\%, respectively. The concentration of Hcy in culture medium was measured before incubation $(t=0)$ and after $24 \mathrm{~h}$ (final timepoint for the rest of the experiments) of incubation with $\mathrm{H} 9 \mathrm{c} 2$ cells to determine the amount of putative degradation and/or uptake of the Hcy during this incubation period.

Determination of intracellular S-Adenosylmethionine (SAM) and S-Adenosylhomocysteine (SAH)

Since previous studies suggested that an increase in $\mathrm{SAH}$ is the culprit in cellular damage due to elevated levels of Hcy, we also determined the intracellular concentration of SAM and $\mathrm{SAH}$ in $\mathrm{H} 9 \mathrm{c} 2$ cells after $24 \mathrm{~h}$ of incubation with $\mathrm{D}, \mathrm{L}-$ Hcy. Tandem mass spectrometry (MS/MS) was used for the determination of SAM/SAH concentrations as previously described [28].

\section{Flow cytometry}

Phosphatidylserine exposure was assessed with FITC-labeled human recombinant annexin-V (Bender Med Systems, Vienna, Austria), while propidium iodide (PI; Bender Med Systems) was used to determine the permeability of the cellular membrane. Experiments were performed in the presence or absence of Z-Asp-Glu-Val-Asp-fluoromethylketone (Z-VAD FMK, $25 \mu \mathrm{M}$, Alexis Biochemicals, Lausen, Switzerland), a general caspase inhibitor, to differentiate between reversible flip-flop of plasma membrane phospholipids, apoptosis and necrosis [23]. After treatment with Hcy, the cells were trypsinized and centrifuged at $400 \mathrm{~g}$ for $5 \mathrm{~min}$ at room temperature. Cells were then washed with serum-free DMEM, and resuspended in serum free DMEM containing annexin V (1:40) for $30 \mathrm{~min}$ in the dark at $37^{\circ} \mathrm{C}$ in a humidified $5 \% \mathrm{CO}_{2} / 95 \%$ air atmosphere. Cells were subsequently washed and resuspended in serum free DMEM containing PI (1:40). Cells were measured with a FACSCalibur (Becton Dickinson, San Jose, CA, USA). Results were analyzed by Cell Quest Pro software (Becton Dickinson).

\section{Detection of caspase- 3 activity}

Cells were grown in a 96-wells plate $(20,000$ cells/well). After treatment with Hcy and/or Z-VAD FMK, cells were lysed and incubated with DEVD-rhodamine 110 substrate (Roche, Mannheim, Germany) for $1 \mathrm{~h}$ at $37^{\circ} \mathrm{C}$. Subsequently the amount of free rhodamine was determined at a microplate fluorescence reader (TECAN spectrafluor, Switzerland). The developed fluorochrome was proportional to the concentration of activated caspase- 3 and could be quantified by a calibration curve of diluted free rhodamine. Each condition was measured in triplo per measurement (total of three measurements).

\section{Immunofluoresence microscopy}

To measure the expression of NOX2 and the putative formation of nitrotyrosin, cells were incubated with or without Hcy for $24 \mathrm{~h}$ in the 4-well chamber slides (Nalge Nunc International, Naperville, IL, USA). Cells were washed with PBS and fixated with $4 \%$ formaldehyde for $10 \mathrm{~min}$ at $37^{\circ} \mathrm{C}$. Cells were subsequently washed with PBS, permeabilized with acetone-methanol (70\%-30\%) for $10 \mathrm{~min}$ at $-20^{\circ} \mathrm{C}$, and then washed again with PBS/Tween$20(0.05 \%$ (v/v) Tween-20 in PBS). Subsequently cells were incubated with primary antibodies against NOX2 and nitrotyrosin for $60 \mathrm{~min}$ at room temperature followed by incubation overnight at $4^{\circ} \mathrm{C}$. PBS and isotype controls were also tested to determine nonspecific binding of the antibodies and background signal. The following day the cells were washed with PBS/Tween and incubated with the secondary antibodies for $30 \mathrm{~min}$ at room temperature. After subsequent washes in PBS/Tween and PBS, the slides were covered in mounting medium containing DAPI (Vector Laboratories Inc, Burlingame, CA, USA) to visualize nuclei. Thereafter the slides were covered with coverslips.

Subsequently, cells were analyzed by means of a 3I Marianas ${ }^{\text {TM }}$ digital imaging microscopy workstation (Zeiss Axiovert 200 M inverted microscope; Carl Zeiss, Sliedrecht, Netherlands), equipped with a nanostepper motor ( $Z$-axis increaments; $10 \mathrm{~nm}$ ) and a cooled CCD camera (Cooke Sensicam, $1280 \times 1024$ pixels; Cooke Co, Tonawanda, NY, USA). Visualization of NOX2 and nitrotyrosine was performed with a $40 \times$ air lens. The microscope, camera and data viewing process were controlled by SlideBook ${ }^{\mathrm{TM}}$ software (version 4.0.8.1; Intelligent Imaging Innovations, Denver, CO, USA).

Live cell analysis of $\Delta \Psi \mathrm{m}$

To visualize mitochondrial membrane potential $\left(\Delta \Psi_{\mathrm{m}}\right)$ via Life Cell Imaging, cells were loaded for $30 \mathrm{~min}$ at $37^{\circ} \mathrm{C}$ with $0.5 \mu \mathrm{mol} / 1$ of $5,5^{\prime}, 6,6^{\prime}$-tetrachloro-1,1',3,3'-tetraethylbenzimidazolylcarbocyanine iodide (JC-1; Cell Technology Inc, Minneapolis, USA). In non-apoptotic cells, JC-1 exists as a monomer and is visible on the green channel (FITC). In healthy cells these monomers accumulate 
as aggregates in the mitochondria due to existing $\Delta \Psi_{\mathrm{m}}$. These aggregates are visible on the red channel (CY3) when viewed with a fluorescence microscope. Cells were washed with PBS before viewing and subsequently analyzed by use of a 3I Marianas ${ }^{\mathrm{TM}}$ digital imaging microscopy workstation as described above.

\section{Western blot analysis}

After treatment $\mathrm{H} 9 \mathrm{c} 2$ cells were harvested into modified ELB lysis buffer $(250 \mathrm{mM} \mathrm{NaCl}, 0.1 \%$ Nonidet P-40, $50 \mathrm{mM}$ HEPES $\mathrm{pH} 7.0,5 \mathrm{mM}$ EDTA, $0.5 \mathrm{mM}$ DTT) wherein protease inhibitor cocktail (PIC, 1:40; Sigma) was added, and the cell suspension was mixed rigorously and then incubated for $30 \mathrm{~min}$ on ice. After determination of the protein concentration of the samples with the BCA protein assay kit (Pierce, Rockford, IL, USA), reducing sample loading buffer $(0.25 \mathrm{M}$ TRIS $\mathrm{pH}$ 6.8, sodium dodecyl sulfate (SDS), glycerol, 2-mercaptoethanol, bromophenol blue) was added and the samples were mixed and heated at $95^{\circ} \mathrm{C}$ for $10 \mathrm{~min}$. A total of $50 \mu \mathrm{g}$ protein of each sample was then subjected to SDS-PAGE, transferred to nitrocellulose membranes and analyzed for NOX2 expression with monoclonal antibody 48 (1:250 dilution) and for pan-actin with monoclonal antibody $1501 \mathrm{R}$ as a loading control (1:6000), followed by horseradish-peroxidase-conjugated rabbit-anti-mouse immunoglobulins (R $\propto$ M-HRP; 1:1000 dilution; DakoCytomation, Glostrup, Denmark). The blots were visualized by enhanced chemiluminescence (ECL; Amersham Biosciences AB; Uppsala; Sweden). Staining was quantified with a charge-coupled device camera (Fuji Science Imaging Systems; Düsseldorf, Germany) in combination with AIDA Image Analyzer software (Isotopenmessgeräte; Staubenhardt, Germany).

\section{ATP measurement via Luciferase-Luciferin assay}

After treatment cells were collected by trypsinization and centrifugation at $400 \mathrm{~g}$ for $5 \mathrm{~min}$. Cells were then counted and equal amounts were taken per condition. After centrifugation for $2 \mathrm{~min}(400 \mathrm{~g})$ the supernatant was discarded. The pellet was resuspended in $150 \mu \mathrm{l}$ of ice-cold perchloric acid (PCA) $0.4 \mathrm{M}$. Cells were left on ice for $30 \mathrm{~min}$ and then centrifuged again for $5 \mathrm{~min}(2000 \mathrm{~g})$ at $4^{\circ} \mathrm{C}$. To the isolated supernatant $7.5 \mu \mathrm{l}$ of $\mathrm{K}_{2} \mathrm{CO}_{3} 5 \mathrm{M}$ was added to neutralize $\mathrm{pH}$. Samples were subsequently stored at $-80^{\circ} \mathrm{C}$ until measuring. The amount of ATP in the samples was determined with a Luciferase-Luciferin assay (Biaffin GmbH \& Co KG, Kassel, Germany) according to the manufacturers' protocol. Samples were measured in a FluoroNunc MaxiSorp plate (Nalge Nunc International, Rochester, NY). Luminescence was measured by using a
Tecan GENios Plus reader (Tecan Benelux, Mechelen, Belgium).

\section{Statistics}

Statistics were performed with the SPSS statistics program (windows version 9.0). To evaluate whether observed differences were significant, One Way ANOVA with post hoc Bonferroni tests were used. All values are expressed as mean \pm standard error of the mean (SEM). A $P$ value (two sided) of 0.05 or less was considered to be significant.

\section{Results}

Measurement of the concentration of D,L-homocysteine (D,L-Hcy), L-homocysteine (L-Hcy), S-adenosyl methionine (SAM) and S-adenosyl homocysteine $(\mathrm{SAH})$

We tested the effects of D,L-Hcy at concentrations of $0.1 \mathrm{mM}, 1.1 \mathrm{mM}$ and $2.7 \mathrm{mM}$, in accordance with previous studies in isolated vascular cells [15, 17, 26, 29-31]. We quantified the exact concentration of D,L-Hcy in medium added to the cells, via HPLC. As depicted in Table 1, the concentration of D,L-Hcy was according to the concentration added to the growth medium.

Since previous studies have shown that only the $\mathrm{L}$ form of Hcy is bioactive [25, 26], we also determined the L-Hcy concentration in medium by IMx. We found that $42.7 \%$, $42.5 \%$ and $43.3 \%$ of the total D,L-Hcy amount $0.1 \mathrm{mM}$, $1.1 \mathrm{mM}$ and $2.7 \mathrm{mM}$, respectively, in fact was L-Hcy at $t=0$. Furthermore, we determined the concentrations of L-Hcy at $24 \mathrm{~h}$, the final time point of incubation, and found a significant decrease in the concentrations of L-Hcy, namely for $1.1 \mathrm{mM}$ a significant decrease of $0.14 \mathrm{mM}$ L-Hcy; $+/-0.011(P<0.001)$ and for $2.7 \mathrm{mM}$ a significant decrease of $0.34 \mathrm{mM} \mathrm{L}-\mathrm{Hcy} ;+/-0.0301(P<0.001)$.

It has been well documented that increased levels of SAH inhibit several important methylation reactions [32-34]. Therefore we also determined the intracellular concentrations of both SAH and SAM, being one of the primary methyl donors (Table 1). Measuring intracellular concentrations of SAM and SAH in H9c2 cells incubated with and without D,L-Hcy showed a significant depletion of SAM at $2.7 \mathrm{mM}$ D,L-Hcy compared to untreated cells and $0.1 \mathrm{mM} \mathrm{D,L-Hcy} \mathrm{treated} \mathrm{cells}(P=0.006 ; n=3)$. While the concentration of SAH increased significantly at this same concentration compared to all other conditions $(P<0.001 ; n=3)$. Therefore we also examined the effects of the higher, non-physiological concentrations of Hcy. 
Table 1 Concentration of D,L-Hcy and L-Hcy in culture medium on $t=0$, L-Hcy after $24 \mathrm{~h}$ incubation, and intra-cellular concentration of SAM/ $\mathrm{SAH}$ after $24 \mathrm{~h}$ incubation

\begin{tabular}{lllllll}
\hline $\mathrm{mM}$ Hcy added & $\mathrm{mM}$ Hcy measured & & & {$[\mathrm{SAM}](\mathrm{nM}) t=24$} & {$[\mathrm{SAH}](\mathrm{nM}) t=24$} \\
\cline { 2 - 4 } & {$[\mathrm{D}, \mathrm{L}-\mathrm{Hcy}]$} & {$[\mathrm{L}-\mathrm{Hcy}] t=0$} & {$[\mathrm{~L}-\mathrm{Hcy}] t=24$} & & \\
\hline 0.0 & 0 & $0.0007(+/-0.00009)$ & $0.002(+/-0.00004)$ & & $464.9(+/-36.6)$ & $6.3(+/-0.7)$ \\
0.1 & $0.14(+/-0.03)$ & $0.06(+/-0.01)$ & $0.06(+/-0.01)$ & & $468.3(+/-77.2)$ & $7.0(+/-2.9)$ \\
1.1 & $1.08(+/-0.04)$ & $0.46(+/-0.03)$ & $0.32(+/-0.01)^{*}$ & & $319.6(+/-56.2)$ & $16.9(+/-6.8)$ \\
2.7 & $2.73(+/-0.06)$ & $1.18(+/-0.05)$ & $0.84(+/-0.03)^{*}$ & & $204.4(+/-74.5)^{* *}$ & $164.8(+/-34.6)^{* * *}$ \\
\hline
\end{tabular}

All mediators were measured in $n=3$. A significant decrease of L-Homocysteine (L-Hcy) can be seen at $1.1 \mathrm{mM}$ and $2.7 \mathrm{mM}$ after $24 \mathrm{~h}$ (* $P<0.001)$. At $2.7 \mathrm{mM}$ a significant decrease of S-adenosylmethionine $\left(\mathrm{SAM},{ }^{* *} P=0.006\right.$ ); but an increase in S-adenosylhomocysteine (SAH, $* * * P<0.001)$ was detected, compared to all other concentrations

Effect of Hcy on cell viability

We analyzed the effect of Hcy on H9c2 cell viability by measuring annexin $\mathrm{V}$ and/or PI positivity using flowcytometry. Incubation with $0.1 \mathrm{mM}$ D,L-Hcy had no effect on single-annexin-V-positivity (Fig. 1A), double-annexinV, PI positivity (Fig. 1B) or single-PI positivity (not shown, approximately $3 \%$ for each condition). In contrast, incubation with $1.1 \mathrm{mM}$ D,L-Hcy resulted in a significant increase in single- annexin-V-positive cells $(P<0.002)$ (Fig. 1A). This increase in single-annexin-V-positive cells was only partly, but not significantly inhibited by Z-VAD FMK (31.6\% decrease). $1.1 \mathrm{mM}$ D,L-Hcy had no significant effect on the percentage of double-annexin-V/PI-positive cells (Fig. 1B) or on the percentage of single-PI-positive cells (not shown). Incubation with $2.7 \mathrm{mM}$ D,L-Hcy, however, resulted in a significant increase of single-annexin- $\mathrm{V}$ positive cells $(P<0.001)$ and double-annexin-V/PI-positive cells $(P<0.044)$ that could not be inhibited significantly by Z-VAD FMK. Again we did not see any significant increase in single-PI-positive cells (not shown). Thus, depending on the concentration of Hcy, either reversibly flip-flopped cardiomyocytes and/or late apoptotic/necrotic cells can be found.

\section{Caspase-3 activity}

To determine whether the population of double-annexin-V/ PI-positive cells consists of late apoptotic cells or necrotic cells, we performed an assay of caspase-3 activity. Incubation with $0.1 \mathrm{mM}$ and $1.1 \mathrm{mM}$ D,L-Hcy did result in a small, but not significant increase in caspase- 3 activity that was completely inhibited when Z-VAD FMK was added. Incubation with $2.7 \mathrm{mM}$ D,L-Hcy for $24 \mathrm{~h}$, however, induced a significant increase of caspase-3 activity $(P<0.001)$ that was also completely inhibited with Z-VAD FMK (Fig. 2). Caspase-3 activity measured at earlier time points $(6$ and $16 \mathrm{~h})$ of Hcy incubation was not significantly increased (results not shown). Thus, significant apoptosis induction of $\mathrm{H} 9 \mathrm{c} 2$ cells was only present at $2.7 \mathrm{mM}$ D,L-Hcy.
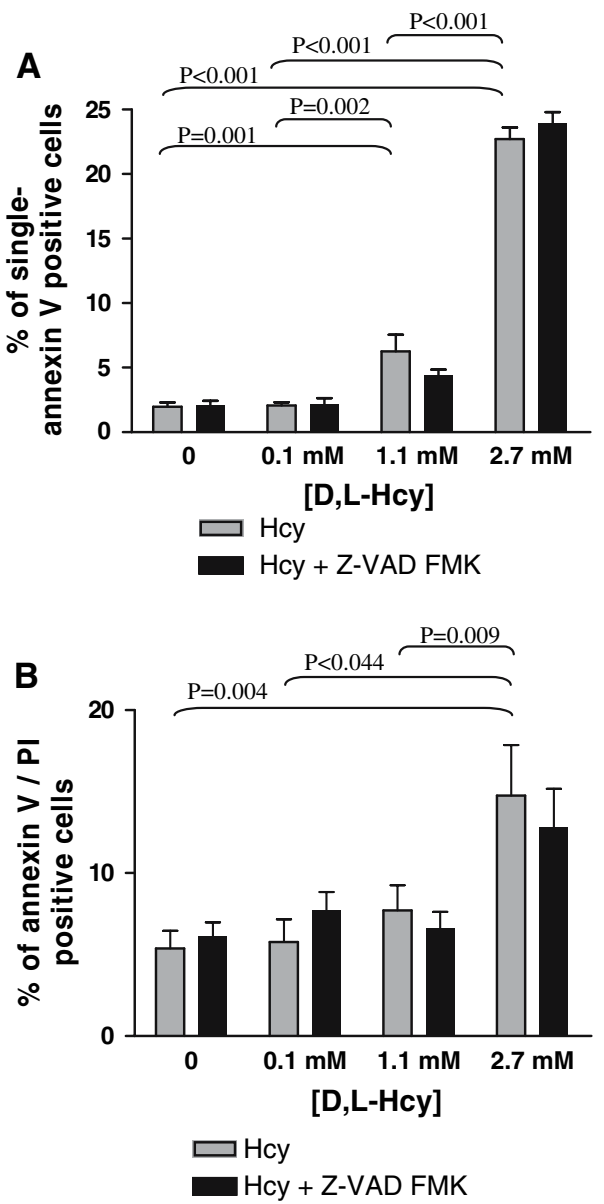

Fig. 1 Effect of Hcy on cell-viability via flow-cytometry: Flow cytometry analysis of $\mathrm{H} 9 \mathrm{c} 2$ cells incubated with different concentrations of D,L-Hcy during $24 \mathrm{~h}$, with or without $25 \mu \mathrm{M} \mathrm{Z}$-VAD FMK, a pan caspase inhibitor. A total of 10,000 cells were measured $(n=3)$. (A) Percentage of single annexin V positive, PI-negative labeled cells, which is a marker of flip flop of the plasma membrane phospholipids. (B) Percentage of double-annexin-V/PI-positive cells depicting late apoptotic and/or necrotic cells. Data represent mean percentages and standard error of the mean (SEM) 


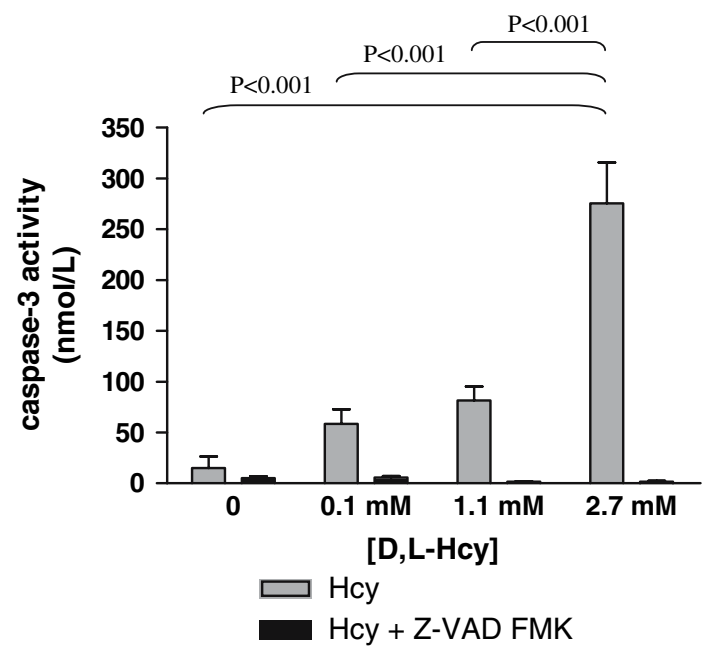

Fig. 2 Effect of Hcy on caspase-3 activity: H9c2 cells were incubated during $24 \mathrm{~h}$ with different concentrations of D,L-Hcy in the presence and absence of Z-VAD FMK $(n=9)$. Caspase- 3 activity was measured as indicated under Methods. Data represent mean and SEM

\section{Effect of Hcy on NOX2 expression and nitrosylation}

In a previous study we have found that ischemia of cardiomyocytes induced nuclear NOX2 expression coinciding with nuclear nitrotyrosine residues, resulting in subsequent apoptosis of these cells [35]. Given the pro-apoptotic effect of $2.7 \mathrm{mM}$ D,L-Hcy, we analyzed by Western blotting the effect of Hcy on NOX2 expression. We found that NOX2 was constitutively present in whole cell lysates of H9c2 cells (Fig. 3). NOX2 expression was slightly increased at $0.1 \mathrm{mM} \mathrm{D}, \mathrm{L}-\mathrm{Hcy}$ and increased even more at concentrations of $1.1 \mathrm{mM}$ and $2.7 \mathrm{mM}$ of D,L-Hcy. It is noteworthy that although we found this increase in NOX2 expression, we were not able to detect apoptosis at the lower concentrations of Hcy. Therefore we subsequently analyzed the intracellular localization of NOX2 with digital imaging. In the cytosol, we found diffuse positivity for NOX2 at all concentrations of Hcy (data not shown). Incubation with $0.1 \mathrm{mM}$ and $1.1 \mathrm{mM}$, but especially with $2.7 \mathrm{mM}$ D,L-Hcy resulted in a significant increase in NOX2 expression in the nucleus $(P<0.001 ; P=0.047 ; P<0.001$, respectively) (Fig. 4A). These results appear in contrast with the caspase-3 measurements. We therefore also analyzed the presence of nitrotyrosine residues as an indicator for ROS production. We found that neither $0.1 \mathrm{mM}$ nor $1.1 \mathrm{mM}$ D,L-Hcy resulted in significant nitrotyrosine formation in the nucleus. In contrast, $2.7 \mathrm{mM}$ D,L-Hcy did induce a significant formation of nitrotyrosine residues in the nucleus $(P<0.001)$ (Fig. 4B). These results underline that not only nuclear NOX2 expression but also nuclear ROS production is necessary for the induction of apoptosis. It
A
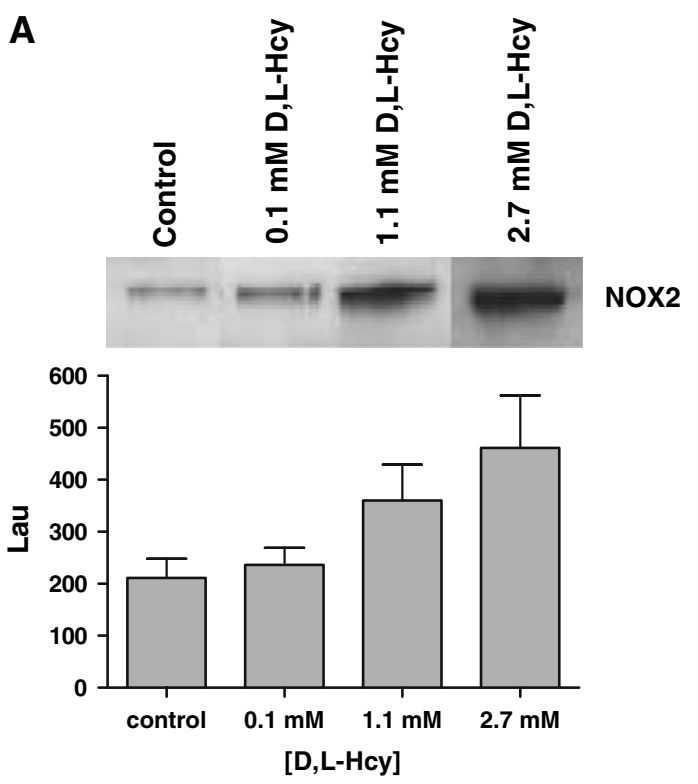

B
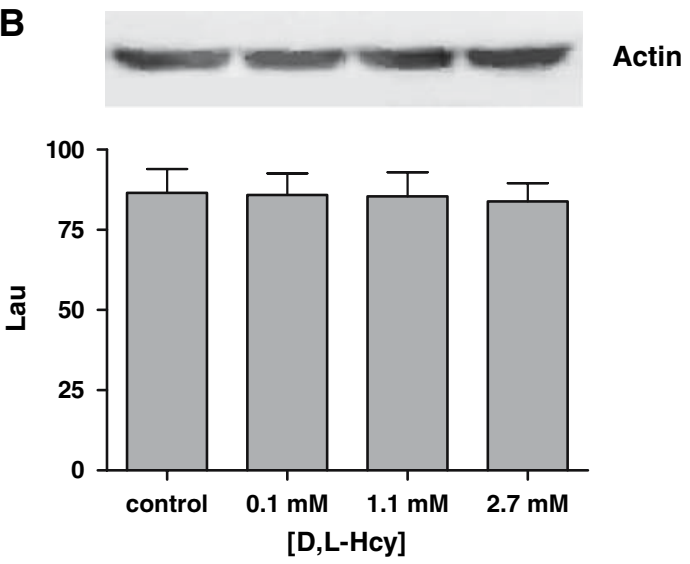

Fig. 3 Effect of Hcy on NOX2 expression: (A) Western Blot analysis for NOX2 expression of whole-cell lysates from $\mathrm{H} 9 \mathrm{c} 2$ cells incubated with or without Hcy for $24 \mathrm{~h}$. Data represent mean and SEM for three independent experiments. (B) Western Blot analysis of the same blots for pan-actin as a loading control

has to be noticed that especially at $2.7 \mathrm{mM} \mathrm{D,L-Hcy} \mathrm{a}$ significant loss of approximately $50 \%$ of the cells was found $(P<0.001$, results not shown). As these cells theoretically are predominantly double-annexin-V/PI or singlePI-positive, we conclude that the effect of incubation with $2.7 \mathrm{mM}$ D,L-Hcy on the amount of double-annexin-V/PI or single-PI-positive cells (see Fig. 1) in all probability is underestimated.

We next wanted to corroborate the findings of NOX2mediated nitrotyrosine formation in adult rat cardiomyocytes. Because the Hcy concentrations analyzed in H9c2 cells were lethally toxic for adult rat cardiomyocytes, we used lower concentrations for these cells. Incubation with $0.07 \mathrm{mM}$ D,L-Hcy induced significant NOX2 expression in 

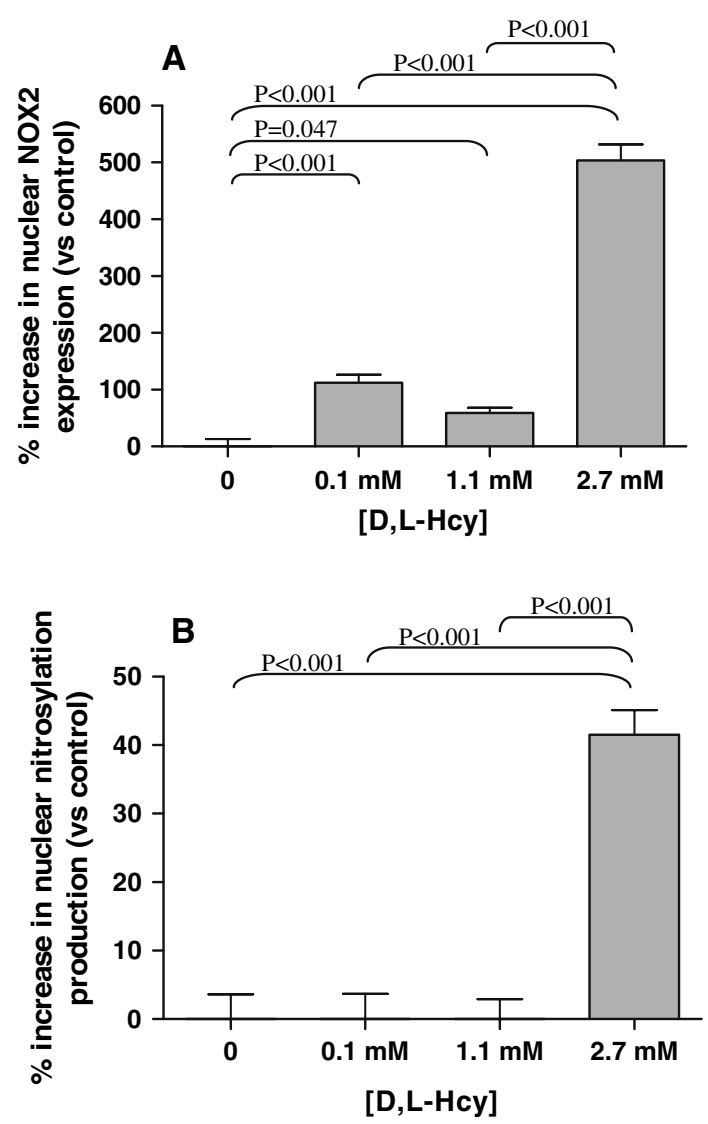

Fig. 4 Effect of Hcy on intracellular localization of NOX2 and nitrosylation in $\mathrm{H} 9 \mathrm{c} 2$ cells: Analysis of the effect of different concentrations of D,L-Hcy at $24 \mathrm{~h}$ incubation on the nuclear localization of NOX2 expression (A) and nitrotyrosine residues (B) measured by means of digital imaging microscopy. The arbitrary units are defined as sum intensity per nucleus and depicted as \% increase versus control where control was set to $0(n=6)$. Data represent mean and SEM

the nucleus $(P<0.022$; Fig. 5D) but no significant nitrotyrosine formation. Incubation with $0.1 \mathrm{mM}$ D,L-Hcy led to significant nuclear NOX2 expression and presence of nitrotyrosine residues $(P<0.01$; Fig. 5A-E). As with H9c2 cells, we found only little NOX2 positivity in the cytosol under all Hcy concentrations analyzed (arrow in Fig. 5A).

\section{ATP depletion}

An important determinant in the process of cell death is ATP, as it is for instance necessary to complete the process of apoptosis. We therefore measured ATP concentrations in H9c2 cells (Fig. 6). Incubation with $0.1 \mathrm{mM}$ D,L-Hcy resulted in a significant increase in ATP concentration $(P=0.05)$. In contrast, incubation with $1.1 \mathrm{mM}$ D,L-Hcy led to a decrease in ATP concentration that was not significant compared to control cells, but was significant compared to ATP concentration found in cells that were incubated with $0.1 \mathrm{mM}$ D,L-Hcy $(P=0.024)$. Incubation with $2.7 \mathrm{mM}$ D,L-Hcy induced an more pronounced decrease of ATP concentration that was significant also when compared to control cells $(P=0.036)$.

$\Delta \Psi_{\mathrm{m}}$

To explain the contrasting effects of different Hcy concentrations on ATP concentrations, we analyzed the mitochondrial membrane potential $\left(\Delta \Psi_{\mathrm{m}}\right)$ with JC-1 staining in $\mathrm{H} 9 \mathrm{c} 2$ cells. We found an increase in red signal $(P=0.006)$ when the $\mathrm{H} 9 \mathrm{c} 2$ cells were incubated with $0.1 \mathrm{mM}$ D,L-Hcy compared to control cells (Fig. 7A/B) which is indicative for more actively respiring mitochondria. $\Delta \Psi_{\mathrm{m}}$ after incubation with $1.1 \mathrm{mM}$ and $2.7 \mathrm{mM}$ D,L-Hcy did not differ significantly from that in control cells (Fig. 7A-E). A difference in the morphology of mitochondria was also visible. In control cells a heterozygous mitochondria population is visible consisting of round and elongated mitochondria. Incubation with $0.1 \mathrm{mM}$ D,L-Hcy showed mostly elongated mitochondria, whereas incubation with $1.1 \mathrm{mM}$ and $2.7 \mathrm{mM}$ D,L-Hcy resulted in a more rounded morphology of the mitochondria, the so called thread-to-grain transition which is seen as an early marker for apoptosis [36].

\section{Discussion}

In the present study we examined the effects of Hcy on cell viability of cardiomyocytes and found different effects, depending on Hcy concentration (Fig. 8).

The lower concentration of $0.1 \mathrm{mM}$ Hcy resulted in mitochondrial hyperpolarization, an increase of ATP and translocation of NOX2 to the nucleus but without local nitrotyrosin formation. Mitochondrial hyperpolarization and an increase in ATP concentration have been described as first signs of mitochondrial disturbance on the pathway to apoptosis [36, 37]. On the other hand, they have also been described as part of a cell-protective mechanism [38]. Therefore, the effect of this lower Hcy concentration may be a cellular state characterized by early activity of both pro- and anti-apoptotic pathways, which does not necessarily result in cell death.

In contrast, the intermediate concentration of $1.1 \mathrm{mM}$ Hcy led to rounding of mitochondria, a slight, non significant decrease of $\Delta \Psi_{\mathrm{m}}$ with a visible thread-to-grain transition of the mitochondrial reticulum, a slight decrease in ATP concentrations, a translocation of NOX2 to the nucleus, again without presence of nitrotyrosin residues, and a flip-flop of the cell membrane phospholipids as 
Fig. 5 Effect of Hcy on intracellular localization of NOX2 and ROS production in adult rat cardiomyocytes: Digital Imaging microscopy pictures of adult rat cardiomyocytes incubated with $0.1 \mathrm{mM}$ D,L-Hcy during $24 \mathrm{~h}$. Red color (A) indicates NOX2 expression which is visible in the nucleus and in the cytosol (arrow). Green color (B) represents nitrotyrosine formation. The merge image

(C) also shows blue DAPI staining for DNA which shows co-localization of NOX2 expression and nitrotyrosine formation in the nucleus. (D) Amount of nuclear NOX2 expression in adult rat cardiomyocyt in control, $0.07 \mathrm{mM}$ and $0.1 \mathrm{mM}$ D,L-Hcy samples $(n=3)$. (E) Amount of nitrotyrosine formation in adult rat cardiomyocyt in control, $0.07 \mathrm{mM}$ and $0.1 \mathrm{mM}$ D,L-Hcy sample $(n=3)$. The arbitrary units are defined as sum intensity per nucleus and depicted as \% increase versus control where control was set to 0 . Data represent mean and SEM
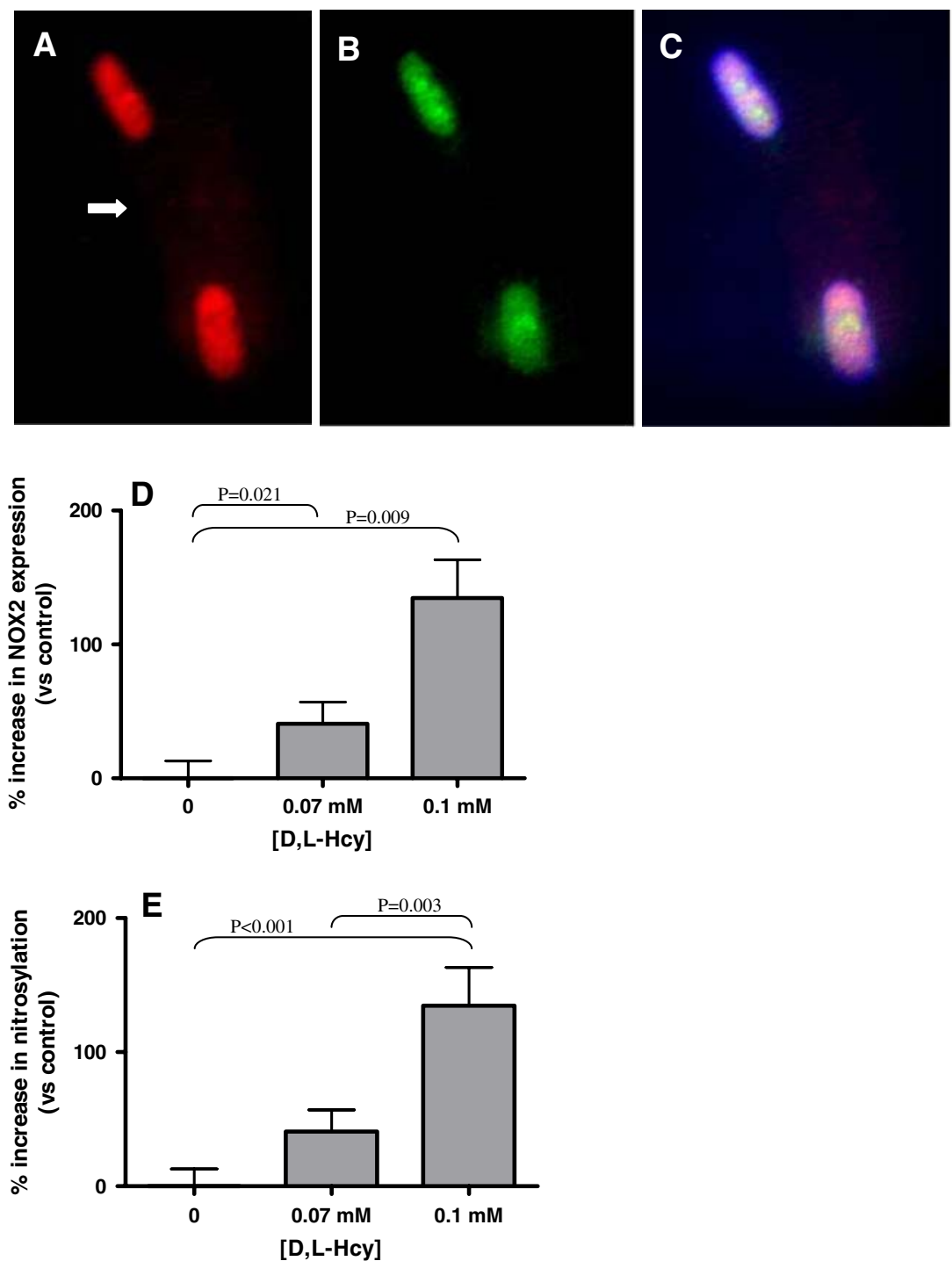

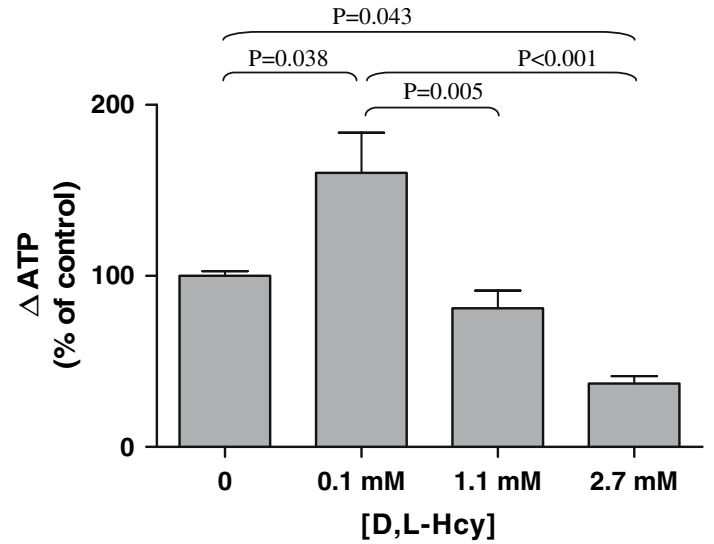

Fig. 6 Effect of Hcy on ATP levels: Increase or decrease in ATP levels (as compared to control levels) in $\mathrm{H} 9 \mathrm{c} 2$ cells after incubation with different concentrations of D,L-Hcy during $24 \mathrm{~h}$. Data represent mean and SEM of four independent experiments indicated by single annexin $\mathrm{v}$ positivity. We did not find caspase-3 activation at this concentration. Although annexin $\mathrm{V}$ positivity of cells has generally been considered as a marker for apoptosis, in a previous study however, we have demonstrated that this is not absolute as such and that membrane phospholipid flip-flop can be reversible [23], which is supported in this study by the observation that complete inhibition of caspases by Z-VAD-FMK did not affect this phenotype. The caspase-dependent pathway of apoptosis was, therefore, not yet activated at this concentration of Hcy, probably related to the lack of nuclear nitrotyrosin residues.

The highest concentration of $2.7 \mathrm{mM}$ Hcy entailed a completion of the thread-to-grain transition of the mitochondrial reticulum, a further decrease of ATP, translocation of NOX2 to the nucleus and nuclear nitrotyrosin formation, caspase- 3 activation, and also a clear increase in 
Fig. 7 Effect of Hcy on mitochondrial membrane potential: H9c2 cells were incubated with or without Hcy for $24 \mathrm{~h}$ and analyzed with digital imaging microscopy. Green indicates the JC-1 monomers. Red indicates JC-1 aggregates, which are formed in the mitochondria when a sufficiently high membrane potential is reached. (A) $\mathrm{H} 9 \mathrm{c} 2$ cells incubated in growth medium alone. Normal heterozygous population of elongated and round mitochondria have a red fluorescence signal. (B) H9c2 cells incubated with $0.1 \mathrm{mM}$ D,L-Hcy. An increase in actively respiring mitochondria (red) is visible, and a mostly elongated morphology can be seen. (C) $1.1 \mathrm{mM}$ D,L-Hcy shows a similar amount of functioning mitochondria in the cells that did not receive Hcy; only the morphology of the mitochondria is mostly round, a phenomenon which is known as thread-tograin transition. (D) $\mathrm{H} 9 \mathrm{c} 2$ cells incubated with $2.7 \mathrm{mM}$ D,L-

Hcy. Some cells have no functioning mitochondria left, but overall there is no significant loss of red signal. The thread-to-grain transition of the mitochondrial reticulum is complete. (E) Analysis of sum intensity in Cy3 signal (red) per condition as an indicator for $\Delta \Psi_{\mathrm{m}}$. Data represent mean and $\operatorname{SEM}(n=3)$

both single-annexin-V and annexin-V/PI-positive cells. These changes represent a cellular phenotype irreversibly committed to cell death, in which nuclear ROS production apparently plays a deciding role as indicated by the presence of nitrotyrosin residues. Whether cell death then follows the process of apoptosis or necrosis depends on the remaining concentration of ATP. Apoptosis is energy consuming, and therefore depends on minimal residual ATP concentrations, whereas necrosis is the default route in the absence of ATP [39].

Induction of apoptosis generally follows one of two pathways. The first pathway, the death receptor or extrinsic pathway, is activated by ligand binding of cell-surfaceexpressed death receptors. The second pathway, the mitochondrial or intrinsic pathway, is promoted by physical or chemical stress agents [40]. Intracellular accumulation of
Hcy and its metabolites constitutes considerable intracellular stress [15, 17, 41]. In line with this notion, several studies in endothelial cells have suggested that Hcy-induced apoptosis follows the mitochondrial pathway $[42,43]$. Our study in cardiomyocytes has shown that $\Delta \Psi_{\mathrm{m}}$ is modified in a concentration-dependent manner, and thereby supports the concept that Hcy-induced apoptosis mainly follows the mitochondrial pathway, also in cardiomyocytes. However, in addition we found that translocation of NOX2 to the nucleus coinciding with the presence of nitrotyrosin residues indicative for ROS production is even more important in the effector phase of the process of apoptosis induction in cardiomyocytes.

Since we only found a significant decrease in L-Hcy at the highest concentrations, but not with $0.1 \mathrm{mM}$ D,L-Hcy we also determined SAH concentrations. Several studies 
Fig. 8 Effects of different concentrations of Hcy on cardiomyocyte viability Scheme of the proposed events caused by Hcy, which ultimately lead to cell death: (A) control cells. (B) $0.1 \mathrm{mM}$ D,L-Hcy results in increase of $\Delta \Psi_{\mathrm{m}}$ and ATP levels, and translocation of NOX2 to the nucleus. (C) $1.1 \mathrm{mM}$ D,L-Hcy results in flipflop of the plasma membrane (bended arrows in plasma membrane indicate flip-flop of phophatidyl serine to the outer leaflet of the membrane), coinciding with localization of NOX2 in the nucleus. (D) $2.7 \mathrm{mM}$ D,L-Hcy next to flipflop and NOX2 localization in the nucleus, nuclear ROS production is found. ATP is then decreased, as well as $\Delta \Psi_{\mathrm{m}}$. Caspase- 3 is activated and PI can enter the cell indicating cell death

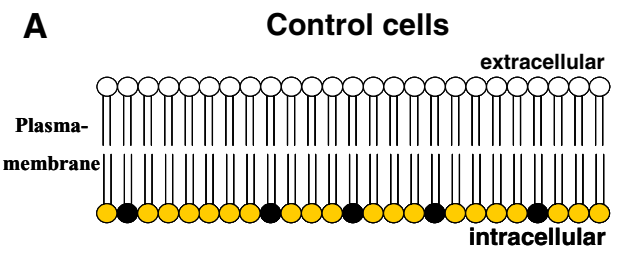

B
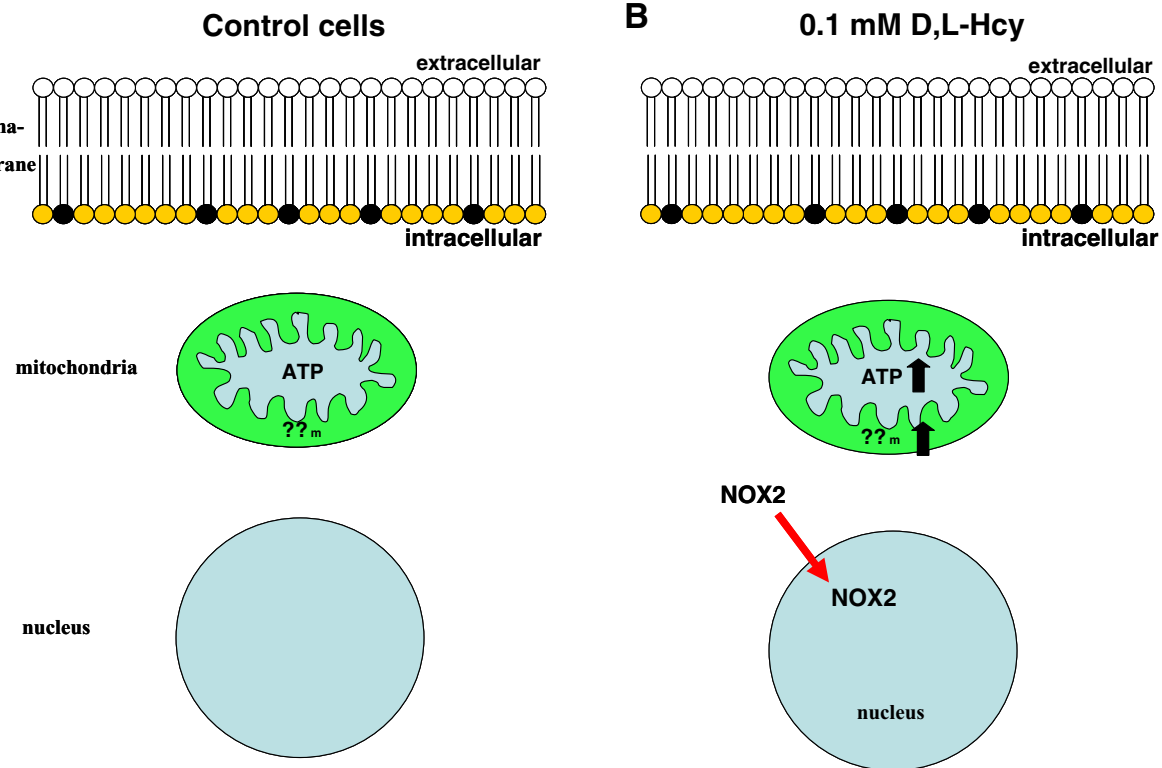

C 1.1 mM D,L-Hcy

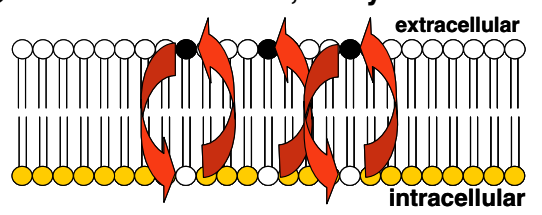

D
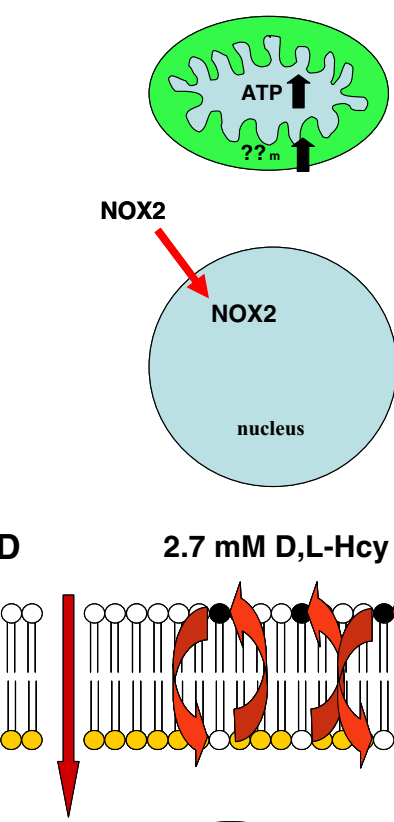

NOX2

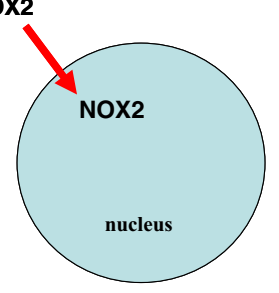

2.7 mM D,L-Hcy

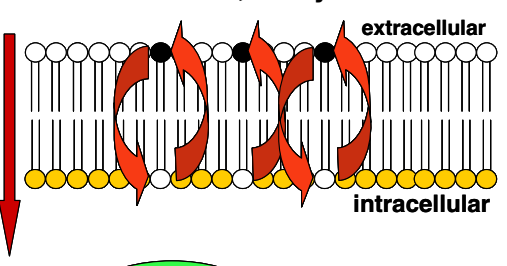

PI

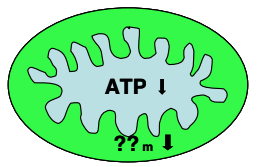

NOX2
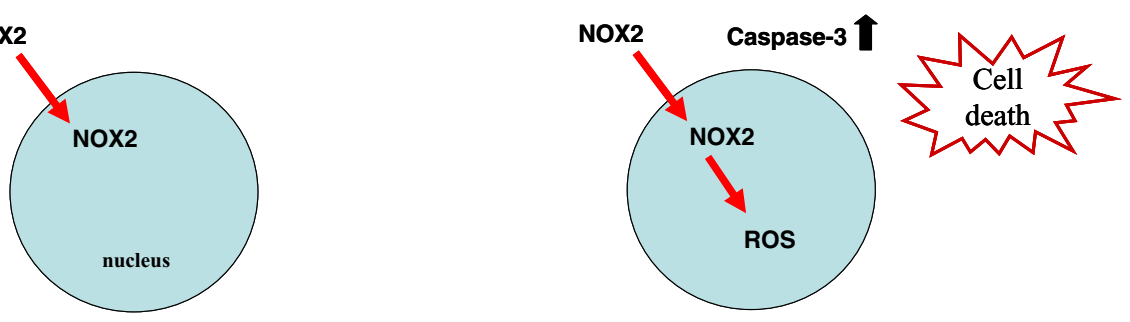

provided further evidence that SAH could be the culprit in Hcy-mediated damage since it is a potent inhibitor of various methylation reactions [32-34]. In this study we found that only the concentration of $2.7 \mathrm{mM}$ D,L-Hcy resulted in a significant increase in SAH, which was the concentration that resulted in cell death of cardiomyocytes. Therefore our study underlines that SAH is an important mediator in the induction of cell death of cardiomyocytes by Hcy.

A limitation of the present study is the use of relatively high concentrations of Hcy. However, it should be noted that cells in culture usually up-regulate their Hcy-metabolizing enzymes, in particular cystathionine beta-synthase (CBS) [44]. Furthermore short-term exposure to high Hcy concentrations may reflect a prolonged exposure to moderately elevated Hcy concentrations as occur life-long in patients. Therefore, our data may provide, at least in part, an explanation why HHC contributes to heart failure.

\section{Conclusion}

Hcy is increasingly recognized as an independent cardiovascular risk factor [5-8] and an extensive literature exists that links Hcy-induced changes in endothelial [15, 26, 45-48] and smooth muscle cells [16, 17, 49-52] to atherosclerotic disease. The Framingham Heart Study also showed that increased plasma Hcy levels are a risk factor 
for the development of heart failure [20]. To our knowledge, no reports have yet been published on the effect of Hcy on cardiomyocytes specifically. Our study now clearly indicates that Hcy, and possible $\mathrm{SAH}$, indeed affects also cardiomyocytes, primarily by inducing apoptosis/necrosis in a concentration-dependent manner, in which nuclear ROS production, related to nuclear NOX2 expression, is crucial.

Acknowledgement This project is financed by the Dutch Heart Foundation (grant 2002B010) and the ICaR-VU (nr. 200370)

\section{References}

1. Welch GN, Loscalzo J (1998) Homocysteine and atherothrombosis. N Engl J Med 338:1042-1050

2. Frosst P, Blom HJ, Milos R et al (1995) A candidate genetic risk factor for vascular disease: a common mutation in methylenetetrahydrofolate reductase. Nat Genet 10:111-113

3. Symons JD, Mullick AE, Ensunsa JL, Ma AA, Rutledge JC (2002) Hyperhomocysteinemia evoked by folate depletion: effects on coronary and carotid arterial function. Arterioscler Thromb Vasc Biol 22:772-780

4. McCully KS (1969) Vascular pathology of homocysteinemia: implications for the pathogenesis of arteriosclerosis. Am J Pathol 56:111-128

5. Coppola A, Davi G, De SV, Mancini FP, Cerbone AM, Di Minno G (2000) Homocysteine, coagulation, platelet function, and thrombosis. Semin Thromb Hemost 26:243-254

6. Al Obaidi MK, Philippou H, Stubbs PJ et al (2000) Relationships between homocysteine, factor VIIa, and thrombin generation in acute coronary syndromes. Circulation 101:372-377

7. Bautista LE, Arenas IA, Penuela A, Martinez LX (2002) Total plasma homocysteine level and risk of cardiovascular disease: a meta-analysis of prospective cohort studies. J Clin Epidemiol 55:882-887

8. Hoogeveen EK, Kostense PJ, Jakobs C et al (2000) Hyperhomocysteinemia increases risk of death, especially in type 2 diabetes: 5-year follow-up of the Hoorn Study. Circulation 101:1506-1511

9. Hung CJ, Huang PC, Lu SC et al (2002) Plasma homocysteine levels in Taiwanese vegetarians are higher than those of omnivores. J Nutr 132:152-158

10. Boers GH (2000) Mild hyperhomocysteinemia is an independent risk factor of arterial vascular disease. Semin Thromb Hemost 26:291-295

11. Toole JF, Malinow MR, Chambless LE et al (2004) Lowering homocysteine in patients with ischemic stroke to prevent recurrent stroke, myocardial infarction, and death: the Vitamin Intervention for Stroke Prevention (VISP) randomized controlled trial. JAMA 291:565-575

12. Lonn E, Yusuf S, Arnold MJ et al (2006) Homocysteine lowering with folic acid and B vitamins in vascular disease. N Engl J Med 354:1567-1577

13. Bonaa KH, Njolstad I, Ueland PM et al (2006) Homocysteine lowering and cardiovascular events after acute myocardial infarction. N Engl J Med 354:1578-1588

14. Loscalzo J (2006) Homocysteine trials-clear outcomes for complex reasons. N Engl J Med 354:1629-1632

15. Au-Yeung KK, Woo CW, Sung FL, Yip JC, Siow YL, Karmin O (2004) Hyperhomocysteinemia activates nuclear factor-kappaB in endothelial cells via oxidative stress. Circ Res 94:28-36
16. Vermeulen EG, Niessen HW, Bogels M, Stehouwer CD, Rauwerda JA, van Hinsbergh VW (2001) Decreased smooth muscle cell/extracellular matrix ratio of media of femoral artery in patients with atherosclerosis and hyperhomocysteinemia. Arterioscler Thromb Vasc Biol 21:573-577

17. Buemi M, Marino D, Di Pasquale G et al (2001) Effects of homocysteine on proliferation, necrosis, and apoptosis of vascular smooth muscle cells in culture and influence of folic acid. Thromb Res 104:207-213

18. Alvarez-Maqueda M, El Bekay R, Monteseirin J et al (2004) Homocysteine enhances superoxide anion release and NADPH oxidase assembly by human neutrophils. Effects on MAPK activation and neutrophil migration. Atherosclerosis 172:229-238

19. Ungvari Z, Csiszar A, Edwards JG et al (2003) Increased superoxide production in coronary arteries in hyperhomocysteinemia: role of tumor necrosis factor-alpha, NAD $(\mathrm{P}) \mathrm{H}$ oxidase, and inducible nitric oxide synthase. Arterioscler Thromb Vasc Biol 23:418-424

20. Sundstrom J, Vasan RS (2005) Homocysteine and heart failure: a review of investigations from the Framingham Heart Study. Clin Chem Lab Med 43:987-992

21. Miller A, Mujumdar V, Palmer L, Bower JD, Tyagi SC (2002) Reversal of endocardial endothelial dysfunction by folic acid in homocysteinemic hypertensive rats. Am J Hypertens 15:157-163

22. Joseph J, Joseph L, Shekhawat NS et al (2003) Hyperhomocysteinemia leads to pathological ventricular hypertrophy in normotensive rats. Am J Physiol Heart Circ Physiol 285:H679-H686

23. Krijnen PA, Cillessen SA, Manoe R et al (2005) Clusterin: a protective mediator for ischemic cardiomyocytes? Am J Physiol Heart Circ Physiol 289:H2193-H2202

24. Verhoeven AJ, Bolscher BG, Meerhof LJ et al (1989) Characterization of two monoclonal antibodies against cytochrome b558 of human neutrophils. Blood 73:1686-1694

25. Weiss N (2005) Mechanisms of increased vascular oxidant stress in hyperhomocys-teinemia and its impact on endothelial function. Curr Drug Metab 6:27-36

26. Poddar R, Sivasubramanian N, DiBello PM, Robinson K, Jacobsen DW (2001) Homocysteine induces expression and secretion of monocyte chemoattractant protein-1 and interleukin8 in human aortic endothelial cells: implications for vascular disease. Circulation 103:2717-2723

27. Ubbink JB, Hayward Vermaak WJ, Bissbort S (1991) Rapid highperformance liquid chromatographic assay for total homocysteine levels in human serum. J Chromatogr 565:441-446

28. Struys EA, Jansen EE, de Meer K, Jakobs C (2000) Determination of S-adenosylmethionine and S-adenosylhomocysteine in plasma and cerebrospinal fluid by stable-isotope dilution tandem mass spectrometry. Clin Chem 46:1650-1656

29. Lang D, Kredan MB, Moat SJ et al (2000) Homocysteine-induced inhibition of endothelium-dependent relaxation in rabbit aorta: role for superoxide anions. Arterioscler Thromb Vasc Biol $20: 422-427$

30. Suhara T, Fukuo K, Yasuda O et al (2004) Homocysteine enhances endothelial apoptosis via upregulation of Fas-mediated pathways. Hypertension 43(6):1208-1213

31. Kerkeni M, Tnani M, Chuniaud L, Miled A, Maaroufi K, Trivin F (2006) Comparative study on in vitro effects of homocysteine thiolactone and homocysteine on HUVEC cells: evidence for a stronger proapoptotic and proinflammative homocysteine thiolactone. Mol Cell Biochem 291:119-126

32. Kredich NM, Jr Martin DV (1977) Role of S-adenosylhomocysteine in adenosinemediated toxicity in cultured mouse T lymphoma cells. Cell 12:931-938

33. Hoffman DR, Cornatzer WE, Duerre JA (1979) Relationship between tissue levels of S-adenosylmethionine, S-adenylhomo- 
cysteine, and transmethylation reactions. Can J Biochem 57: $56-65$

34. Castro R, Rivera I, Martins C et al (2005) Intracellular S-adenosylhomocysteine increased levels are associated with DNA hypomethylation in HUVEC. J Mol Med 83:831-836

35. Meischl C, Krijnen PA, Sipkens JA et al (2006) Ischemia induces nuclear NOX2 expression in cardiomyocytes and subsequently activates apoptosis. Apoptosis 11(6):913-921

36. Skulachev VP, Bakeeva LE, Chernyak BV et al (2004) Threadgrain transition of mitochondrial reticulum as a step of mitoptosis and apoptosis. Mol Cell Biochem 256-257:341-358

37. Di Stefano A, Frosali S, Leonini A et al (2006) GSH depletion, protein S-glutathionylation and mitochondrial transmembrane potential hyperpolarization are early events in initiation of cell death induced by a mixture of isothiazolinones in HL60 cells. Biochim Biophys Acta 1763:214-225

38. Kawahara K, Hachiro T, Yokokawa T, Nakajima T, Yamauchi Y, Nakayama Y (2006) Ischemia/reperfusion-induced death of cardiac myocytes: possible involvement of nitric oxide in the coordination of ATP supply and demand during ischemia. J Mol Cell Cardiol 40:35-46

39. Leist M, Single B, Castoldi AF, Kuhnle S, Nicotera P (1997) Intracellular adenosine triphosphate (ATP) concentration: a switch in the decision between apoptosis and necrosis. J Exp Med 185:1481-1486

40. Czerski L, Nunez G (2004) Apoptosome formation and caspase activation: is it different in the heart? J Mol Cell Cardiol 37: 643-652

41. Outinen PA, Sood SK, Pfeifer SI et al (1999) Homocysteineinduced endoplasmic reticulum stress and growth arrest leads to specific changes in gene expression in human vascular endothelial cells. Blood 94:959-967

42. Tyagi N, Ovechkin AV, Lominadze D, Moshal KS, Tyagi SC (2006) Mitochondrial mechanism of microvascular endothelial cells apoptosis in hyperhomocysteinemia. J.Cell Biochem 98(5):1150-1162

43. Austin RC, Sood SK, Dorward AM et al (1998) Homocysteinedependent alterations in mitochondrial gene expression, function and structure. Homocysteine and $\mathrm{H}_{2} \mathrm{O}_{2}$ act synergistically to enhance mitochondrial damage. J Biol Chem 273:30808-30817

44. Taoka S, Ohja S, Shan X, Kruger WD, Banerjee R (1998) Evidence for heme-mediated redox regulation of human cystathionine beta-synthase activity. J Biol Chem 273: 25179-25184

45. Jin L, Abou-Mohamed G, Caldwell RB, Caldwell RW (2001) Endothelial cell dysfunction in a model of oxidative stress, Med Sci Monit 7:585-591

46. Vignini A, Nanetti L, Bacchetti T, Ferretti G, Curatola G, Mazzanti L (2004) Modification induced by homocysteine and low-density lipoprotein on human aortic endothelial cells: an in vitro study. J Clin Endocrinol Metab 89:4558-4561

47. Wang H, Yoshizumi M, Lai K et al (1997) Inhibition of growth and p21ras methylation in vascular endothelial cells by homocysteine but not cysteine. J Biol Chem 272:25380-25385

48. Wang Y, Zhou Q, Wang S, Zhang J (2004) [Homocysteine-induced apoptosis of endothelial cell and its antagonism by folic acid - the roles of caspase3, c-IAP1 and c-IAP2]. Wei Sheng Yan Jiu 33:310-313

49. Carmody BJ, Arora S, Avena R, Cosby K, Sidawy AN (1999) Folic acid inhibits homocysteine-induced proliferation of human arterial smooth muscle cells. J Vasc Surg 30:1121-1128

50. Majors A, Ehrhart LA, Pezacka EH (1997) Homocysteine as a risk factor for vascular disease. Enhanced collagen production and accumulation by smooth muscle cells. Arterioscler Thromb Vasc Biol 17:2074-2081

51. Majors AK, Sengupta S, Jacobsen DW, Pyeritz RE (2002) Upregulation of smooth muscle cell collagen production by homocysteine-insight into the pathogenesis of homocystinuria. Mol Genet Metab 76:92-99

52. Nonaka H, Tsujino T, Watari Y, Emoto N, Yokoyama M (2001) Taurine prevents the decrease in expression and secretion of extracellular superoxide dismutase induced by homocysteine: amelioration of homocysteine-induced endoplasmic reticulum stress by taurine. Circulation 104:1165-1170 